\title{
High-Flow Nasal Cannula for Chronic Obstructive Pulmonary Disease with Acute Compensated Hypercapnic Respiratory Failure: A Randomized, Controlled Trial
}

This article was published in the following Dove Press journal:

International Journal of Chronic Obstructive Pulmonary Disease

\begin{abstract}
Xu-Yan Li, ${ }^{1-4, *}$ Xiao Tang, (D) ${ }^{1-4, *}$ Rui Wang, ${ }^{1-4}$ Xue Yuan, ${ }^{1-4}$ Yu Zhao, ${ }^{\text {-4 }}$ Li Wang, ${ }^{\text {I-4 }}$ HaiChao Li, ${ }^{\mathrm{I}-4}$ Hui-Wen Chu, ${ }^{\mathrm{I}-4}$ Jie Li, ${ }^{5}$ Wen-Ping Mao, ${ }^{5}$ YuJun Wang, ${ }^{6}$ Zhan-Hong Tian, ${ }^{6}$ JianHua Liu, ${ }^{6}$ Qin Luo, ${ }^{7}$ Bing Sun, ${ }^{1-4}$ Zhao-Hui Tong ${ }^{1-4}$

'Department of Respiratory and Critical Care Medicine, Beijing Chao-Yang Hospital, Capital Medical University, Beijing, People's Republic of China; ${ }^{2}$ Beijing Institute of Respiratory Medicine, Beijing, People's Republic of China; ${ }^{3}$ Beijing Key Laboratory of Respiratory and Pulmonary Circulation Disorders, Beijing, People's Republic of China; ${ }^{4}$ Beijing Engineering Research Centre for Diagnosis and Treatment of Respiratory and Critical Care Medicine (Beijing Chao-Yang Hospital), Beijing, People's Republic of China; ${ }^{5}$ Department of Respiratory and Critical Care Medicine, Beijing Chao-Yang Hospital-West Branch, Beijing, People's Republic of China; ' $D$ Department of Respiratory and Critical Care Medicine, Beijing Huai-Rou Hospital of University of Chinese Academy of Science, Beijing, People's Republic of China; ${ }^{7}$ Department of Respiratory Neurology, Cancer Hospital of Xinjiang Medical University, Urumqi, Xinjiang Uygur Autonomous Region, People's Republic of China
\end{abstract}

*These authors contributed equally to this work

Correspondence: Bing Sun

Department of Respiratory and Critica Care Medicine, Beijing Chao-Yang Hospital, Capital Medical University, No. 8 Gongrentiyuguannan Road, Chaoyang, Beijing 100020, People's Republic of China $\mathrm{Tel}+861085231543$

Email ricusunbing@I26.com
Introduction: Currently, there is a lack of evidence on the utilization of high-flow nasal cannula (HFNC) in patients with acute exacerbation of chronic obstructive pulmonary disease (AECOPD) accompanied by hypercapnic respiratory failure. We aimed to explore the efficacy and safety of HFNC compared with conventional oxygen therapy (COT) in such patients.

Methods: This was a prospective, randomized, controlled trial. Patients with AECOPD with a baseline arterial blood gas $\mathrm{pH} \geq 7.35, \mathrm{PaO}_{2}<60 \mathrm{mmHg}$, and $\mathrm{PaCO}_{2}>45 \mathrm{mmHg}$ were enrolled. The primary endpoint was treatment failure, which needs mechanical ventilation.

Results: A total of 320 patients were randomized to either the HFNC group $(n=160)$ or the COT group $(n=160)$. Sixteen $(10.0 \%)$ patients in the HFNC group had treatment failure during hospitalization, which was significantly lower than the COT group figure of 31 $(19.4 \%)$ patients $(p=0.026)$. Twenty-four hours after recruitment, the $\mathrm{PaCO}_{2}$ of the HFNC group was lower than that of the COT group $(54.1 \pm 9.79 \mathrm{mmHg}$ vs $56.9 \pm 10.1$ $\mathrm{mmHg}, p=0.030$ ). $\mathrm{PaCO}_{2}$ higher than $59 \mathrm{mmHg}$ after HFNC for $24 \mathrm{~h}$ was identified as an independent risk factor for treatment failure [OR 1.078, 95\% CI 1.006-1.154, $p=0.032$ ].

Conclusion: In AECOPD patients with acute compensated hypercapnic respiratory failure, HFNC improved the prognosis compared with COT. Therefore, HFNC might be considered for first-line oxygen therapy in select patients.

Trial Registration Number: ClinicalTrials.Gov: NCT02439333.

Keywords: chronic obstructive pulmonary disease, exacerbation, high-flow nasal cannula, conventional oxygen therapy, hypercapnic respiratory failure

\section{Introduction}

Chronic obstructive pulmonary disease (COPD) is marked by airflow limitation with persistent and progressive courses of breathlessness, and is frequently associated with chronic productive cough and chest tightness. ${ }^{1}$ COPD is currently the fourth leading cause of death in the world ${ }^{2}$ but is projected to be the third leading cause of death by $2020 .^{3}$ Acute exacerbation of COPD (AECOPD) is an important event in the management of COPD because it negatively impacts patients' health, hospitalization and readmission rates, and disease progression. $\mathrm{CO}_{2}$ retention appears as AECOPD progresses, and the critical condition of AECOPD can manifest as hypercapnic respiratory failure. 
Noninvasive mechanical ventilation (NIV) has been shown to improve gas exchange, reduce the work of breathing and the need for intubation, decrease hospitalization duration, and improve survival. ${ }^{4,5}$ In the 2020 Global Initiative for Chronic Obstructive Lung Disease (GOLD) reports, ${ }^{3}$ NIV was proposed as the first mode of ventilation in AECOPD cases with acute respiratory failure who had no absolute contraindication. A multicenter, randomized, controlled trial from our previous study ${ }^{6}$ indicated that early use of NIV in mild AECOPD cases with a $\mathrm{pH}>7.25$ and a partial pressure of carbon dioxide $\left(\mathrm{PaCO}_{2}\right)>45 \mathrm{mmHg}$ can effectively alleviate respiratory muscle fatigue. However, discomfort and intolerability have restricted the widespread application of NIV in such patients; ${ }^{7,8}$ therefore, conventional oxygen therapy (COT) such as nasal catheter or venturi mask is still the main respiratory support method.

High-flow nasal cannula (HFNC) is a novel, noninvasive respiratory support technique involving the delivery of a totally conditioned, warmed, and humidified airoxygen mixture through a nasal cannula at high flow. ${ }^{9}$ Data have shown that some mild AECOPD cases do not have severe respiratory failure but do have severe respiratory muscle fatigue. ${ }^{6}$ Some clinical data of HFNC in hypercapnic respiratory failure cases showed that it could reduce the inspiratory effort ${ }^{10}$ or decrease transcutaneous carbon dioxide tension ${ }^{11}$ to a greater extent compared with COT. A systematic review showed HFNC might play a role in the treatment of both stable and exacerbated COPD patients. ${ }^{12}$ Therefore, we hypothesize that the application of HFNC may benefit AECOPD patients with mild hypercapnia while improving patient comfort.

This prospective, randomized, controlled study aimed at exploring the efficacy and safety of HFNC in AECOPD patients with acute compensated hypercapnic respiratory failure.

\section{Materials and Methods Study Design and Patients}

This was a tri-center, prospective, randomized, controlled clinical trial (ClinicalTrials. Gov: NCT02439333) conducted in Beijing, China. Patients were recruited from general wards of respiratory departments in three tertiary hospitals beginning in June 2015 and completed in July 2019.

Patients who met the diagnostic criteria ${ }^{13}$ of AECOPD accompanied with compensated hypercapnic respiratory failure, and who were aged 40 years or older, were eligible for this study. Compensated hypercapnic respiratory failure was defined as the baseline arterial blood gas analysis (measured with room air in the supine position after at least 30 min of rest) results of $\mathrm{pH} \geq 7.35$, partial arterial oxygen pressure $\left(\mathrm{PaO}_{2}\right)<60 \mathrm{mmHg}$, and $\mathrm{PaCO}_{2}>45$ mmHg.

Exclusion criteria were as follows: inclusion in this study within three months, refusal of the use of HFNC, long-term NIV at home, respiratory failure requiring mechanical ventilation at admittance, isolated cardiogenic pulmonary edema indicating NIV, gastrointestinal hemorrhage, pneumothorax, or life-threatening organ dysfunction.

The study protocol was approved by the ethics committee of all the participating centers (2015-KE-63), and informed consent was obtained from the patients themselves. This trial was conducted in accordance with the Declaration of Helsinki.

\section{Randomization}

Since admission, eligible patients were randomly assigned (in a 1:1 ratio) to either the HFNC group or COT group for respiratory support throughout the hospitalization period. Randomization was stratified through the leading center. The statistician of the leading center produced computergenerated block randomization lists with a block size of four patients. The treating physician was the study investigator. The nature of the intervention precluded the ability to perform a blinded experiment, so staff members who performed HFNC and COT were aware of the treatment assigned to every patient. However, during the whole study period, the data collection and endpoint judgement were blinded, and the statisticians were also blinded during the statistical analysis. Baseline data, including demographics, medical history, pulmonary function, and laboratory examination, were acquired during randomization.

\section{Interventions}

All the patients received optimized AECOPD therapy ${ }^{14}$ in addition to oxygen therapy. The HFNC or COT oxygen therapy started within 15 min after randomization.

In the HFNC group, high-flow devices (AIRVOTM 2; Fisher \& Paykel Healthcare, Auckland, New Zealand) were utilized for respiratory support. The sizes of the nasal cannulas (Fisher \& Paykel) were chosen based on patients' nostrils. Humidifier temperature was set to $31^{\circ} \mathrm{C}$, $34^{\circ} \mathrm{C}$, or $37^{\circ} \mathrm{C}$ according to the comfort degree of the patients, and the fraction of inspired oxygen $\left(\mathrm{FiO}_{2}\right)$ was 
adjusted to maintain oxygen saturation by pulse oximetry $\left(\mathrm{SpO}_{2}\right)$ at $90 \%$ to $93 \%$. The maximum flow rate also had to be adjusted according to the patients' maximum tolerance. Patients were instructed to use HFNC for at least 15 $\mathrm{h}$ per day, and the total treatment time had to be no less than $5 \mathrm{~d}$.

In the COT group, oxygen was delivered via nasal prongs for at least $15 \mathrm{~h}$ per day. Oxygen flow was set to achieve $\mathrm{SpO}_{2}$ at $90 \%$ to $93 \%$.

\section{Endpoints}

The primary endpoint was defined as treatment failure, which meant the patients required noninvasive or invasive mechanical ventilation (NIV or IMV) because of persistent or worsening dyspnea, persistent abdominal paradox, respiratory rate of more than 25 breaths per minute, and/ or $\mathrm{pH}$ of less than 7.35. In both groups, the final decision on whether a patient should be switched to mechanical ventilation or continue with the original oxygen therapy strategy was made by the attending clinician.

The secondary endpoints included respiratory rate, arterial blood gas analysis (ABG), COPD assessment test (CAT) scores, comfort score, the length of hospitalization, in-hospital mortality, and readmission rate within three months.

Patients were observed until discharge or death. The respiratory rate, blood pressure, temperature, $\mathrm{ABG}$, parameters of HFNC and COT, symptoms, CAT score, and comfort score were collected every day. Data were collected prospectively using an electronic case report form.

\section{Statistical Analysis}

According to the previous research results, ${ }^{6,15}$ early use of non-invasive respiratory support for patients with AECOPD could reduce the tracheal intubation rate from $11.3 \%$ to $2.8 \%$, and there was no difference in the intubation rate between HFNC and $\mathrm{NIV}^{15}(\alpha=5 \% ; \beta=20 \%$, power $=80 \%$ ). Using the superiority test, we calculated a sample size of 160 patients for each group.

Categorical variables were summarized using frequencies and percentages, and continuous data were presented in terms of mean and standard deviation (SD) or median and interquartile range (IQR). Comparisons of clinical characteristics between the two groups were performed using a Students' $t$-test or Wilcoxon rank sum test for continuous variables, and using a $\chi^{2}$ test or Fisher's exact test for categorical variables. Repeated measures analysis of two-way analysis of variance (ANOVA) followed by Bonferroni's test or repeated measures analysis of oneway ANOVA followed by Dunnett's test was performed for the data obtained at multiple points in time. The primary and secondary outcomes were assessed using the Kaplan-Meier approach with the log rank test. Because data from all participants entered into this trial were available for the final statistical analysis, analysis on an intention-to-treat basis was not necessary. Univariate analysis for stratification variables used logistic regression analysis, and the time variable was estimated using the Cox proportional-risk model. We used the receiver operating characteristic (ROC) curve to confirm the cutoff value to predict treatment failure. Variables with a $p$ value of $<0.05$ in the univariate analysis were entered into multivariate logistic regression analysis to identify independent risk factors associated with HFNC failure. We deemed a two-tailed $p$ value of $<0.05$ to be significant. All of the analyses were performed using SPSS (SPSS 21.0 for windows; SPSS; Chicago, IL).

\section{Results}

From June 2015 to July 2019, a total of 1891 patients with AECOPD were screened, of which 524 patients met the inclusion criteria. Among these patients, 204 patients met the exclusion criteria. The remaining 320 patients were randomized to either the HFNC group $(\mathrm{n}=160)$ or COT group ( $\mathrm{n}=160$; Figure 1 , Table S1). No patient was excluded on the basis of missing or incomplete data. The cause of exacerbation was respiratory tract infection in all patients.

The 320 randomized patients had a mean age of $68.4 \pm$ 7.2 years, and 207 of the patients $(64.6 \%)$ were male. The mean time of COPD history in these patients was $15.7 \pm$ 12.7 years. The $\mathrm{ABG}$ at randomization showed that $\mathrm{pH}$ was $7.39 \pm 0.04, \mathrm{PaCO}_{2}$ was $54.6 \pm 6.6 \mathrm{mmHg}$, and $\mathrm{PaO}_{2}$ was $54.8 \pm 5.1 \mathrm{mmHg}$. There were no significant differences in the demographics or clinical characteristics of patients between the two groups at randomization (Table 1).

\section{Endpoint}

For the primary endpoint, $16 / 160(10.0 \%)$ patients experienced treatment failure during hospitalization after randomization in the HFNC group, which was significantly lower than the COT group of $31 / 160$ (19.4\%) patients $(p=0.026$; Table 2, Figure 2). Thirteen (8.1\%) patients 


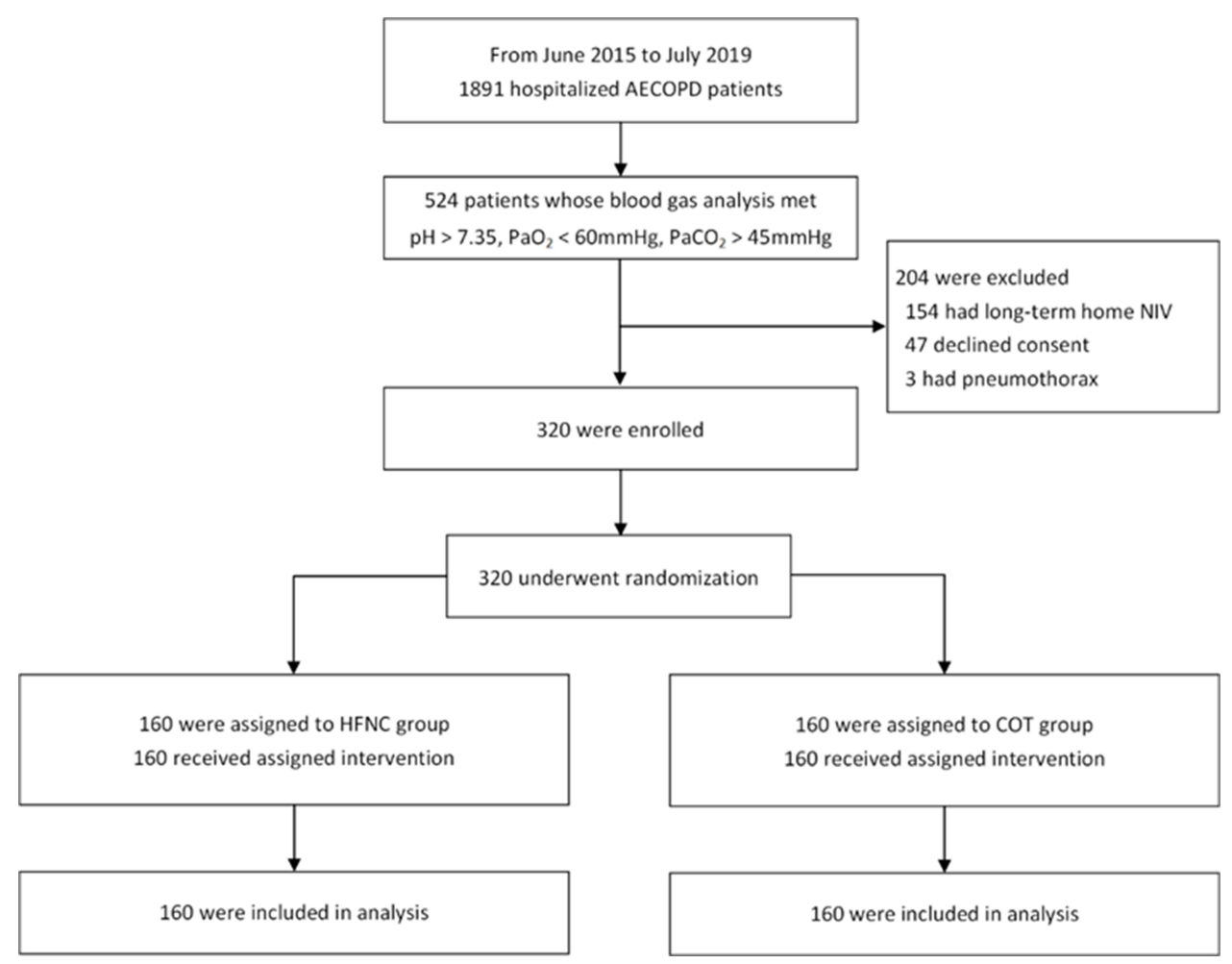

Figure I Flow of patients with acute exacerbation of chronic obstructive pulmonary disease through the trial.

Abbreviations: AECOPD, acute exacerbation of chronic obstructive pulmonary disease; COT, conventional oxygen therapy; HFNC, high-flow nasal cannula; NIV, noninvasive ventilation; $\mathrm{PaO}_{2}$, partial pressure of oxygen; $\mathrm{PaCO}_{2}$, partial pressure of carbon dioxide.

in the HFNC group received NIV because of treatment failure, which was significantly lower than the 26 $(16.3 \%)$ patients of the COT group $(p=0.039)$. None of the patients were intubated or experienced IMV. No complications of NIV during the hospital stay were observed during the study (Table 2).

Twenty-four hours after treatment, the $\mathrm{PaCO}_{2}$ in the HFNC group was significantly lower than that in the COT group $(54.1 \pm 9.8 \mathrm{mmHg}$ vs $56.9 \pm 10.1 \mathrm{mmHg}$, $p=0.030)$. The respiratory rate was also significantly lower in the HFNC group than in the COT group (21.5 \pm 2.0 breaths per min vs $23.1 \pm 7.6$ breaths per $\min , p=$ 0.024; Table 3). In the dynamic observation during the first $5 \mathrm{~d}$ of therapy, the $\mathrm{PaO}_{2}$ increased and $\mathrm{PaCO}_{2}$ decreased significantly over time in both groups. Additionally, there were no significant differences in the levels of $\mathrm{PaO}_{2}$ or $\mathrm{PaCO}_{2}$ between the two groups (Table 3, Figure 3).

CAT score at discharge was $16.3 \pm 7.2$ in the HFNC group, which was significantly lower than $20.4 \pm 5.7$ in the COT group, $p=0.002$. Moreover, the subjective discomfort score of the HFNC group on the fifth day was significantly lower than that of the COT group $(2.27 \pm 1.06$ vs $3.88 \pm 1.64, p<0.001)$. Furthermore, there were no differences in the ABG parameters between the two groups when discharged or during hospitalization. The readmission rate after three months had no difference between the two groups (Table 2).

\section{Risks of Treatment Failure in the HFNC Group}

Sixteen of 160 patients in the HFNC group experienced treatment failure (Table S2). In the successful cases, $\mathrm{PaO}_{2}$ increased and $\mathrm{PaCO}_{2}$ decreased dynamically over time during the treatment process, $p<0.001$. However, this improvement was not observed in the treatment-failure group. The level of $\mathrm{PaCO}_{2}$ in the first five days of dynamic observation was significantly lower in successful cases than in failed ones, $p<0.001$ (Table 4, Figure 4). Moreover, the ROC curve showed the cutoff value to predict that treatment failure was $59 \mathrm{mmHg}$, with a sensitivity of 0.571 and a specificity of 0.754 . In the multivariate logistic regression analysis, $\mathrm{PaCO}_{2}>59$ $\mathrm{mmHg}$ at $24 \mathrm{~h}$ after HFNC was identified as an independent risk factor for treatment failure (OR 1.078, 95\% CI [1.006-1.154], $p=0.032$; Table 5). 
Table I Characteristics of Patients at Randomization

\begin{tabular}{|c|c|c|}
\hline Characteristic & $\begin{array}{l}\text { HFNC Group } \\
(n=160)\end{array}$ & $\begin{array}{l}\text { СОT Group } \\
(n=160)\end{array}$ \\
\hline Age (years) & $68.4 \pm 7.7$ & $68.3 \pm 6.9$ \\
\hline Male no. (\%) & $101(63.1)$ & $106(66.2)$ \\
\hline Body mass index $\left(\mathrm{kg} / \mathrm{m}^{2}\right)$ & $23.1 \pm 4.5$ & $22.7 \pm 3.9$ \\
\hline COPD history(years) & $16.8 \pm 13.4$ & $14.6 \pm 12.1$ \\
\hline Smoking history (years) & $22.4 \pm 12.5$ & $23.5 \pm 12.3$ \\
\hline Current smokers no. (\%) & $102(63.8)$ & $108(67.5)$ \\
\hline CAT scores & $20.3 \pm 5.5$ & $21.5 \pm 5.5$ \\
\hline APACHE II scores & $15.8 \pm 6.5$ & $14.7 \pm 6.0$ \\
\hline \multicolumn{3}{|l|}{ Comorbidity, no. (\%) } \\
\hline Hypertension & $35(21.9)$ & $37(23.1)$ \\
\hline Diabetes mellitus & $17(10.6)$ & $20(12.8)$ \\
\hline Coronary heart disease & $20(12.5)$ & $12(7.5)$ \\
\hline Cerebrovascular Disease & $9(5.6)$ & $\mathrm{II}(6.8)$ \\
\hline Obsolete Pulmonary Tuberculosis & $7(4.6)$ & 6(3.7) \\
\hline \multicolumn{3}{|l|}{ Baseline spirometry } \\
\hline Pre-bronchodilator FEVI (L) & $1.47 \pm 0.54$ & $1.54 \pm 0.6 \mathrm{I}$ \\
\hline Post-bronchodilator FEVI (L) & $1.7 I \pm 0.56$ & $1.7 I \pm 0.63$ \\
\hline $\begin{array}{l}\text { Post-bronchodilator FEVI, \% } \\
\text { predicted }\end{array}$ & $61.2 \pm 18.1$ & $59.9 \pm 18.2$ \\
\hline $\begin{array}{l}\text { Post-bronchodilator FEVI/FVC } \\
\text { ratio, \% }\end{array}$ & $53.6 \pm 10.6$ & $51.9 \pm 10.4$ \\
\hline \multicolumn{3}{|l|}{ Vital signs } \\
\hline Body temperature $\left({ }^{\circ} \mathrm{C}\right)$ & $36.3 \pm 2.5$ & $36.5 \pm 0.4$ \\
\hline Heart rate (beats/min) & $91.5 \pm 16.2$ & $90.1 \pm 14.5$ \\
\hline Mean arterial pressure $(\mathrm{mmHg})$ & $92.6 \pm 12.9$ & $95.1 \pm 12.7$ \\
\hline Respiratory rate (breaths/min) & $21.0 \pm 1.7$ & $21.1 \pm 1.9$ \\
\hline \multicolumn{3}{|l|}{ Arterial blood gas (room air) } \\
\hline $\mathrm{pH}$ & $7.38 \pm 0.03$ & $7.39 \pm 0.04$ \\
\hline $\mathrm{PaO}_{2}(\mathrm{mmHg})$ & $54.7 \pm 5.2$ & $54.9 \pm 4.9$ \\
\hline $\mathrm{PaCO}_{2}(\mathrm{mmHg})$ & $54.9 \pm 7.1$ & $54.2 \pm 6.0$ \\
\hline BE & $6.6 \pm 3.6$ & $6.2 \pm 4.1$ \\
\hline $\mathrm{HCO}^{-}$ & $32.9 \pm 3.8$ & $31.9 \pm 4.6$ \\
\hline \multicolumn{3}{|l|}{ Laboratory parameters } \\
\hline White blood cell $\left(\times 10^{9} / \mathrm{L}\right)$ & $7.7 \pm 4.6$ & $8.2 \pm 4.1$ \\
\hline Neutrophil (\%) & $66.8 \pm 19.3$ & $67.0 \pm 18.0$ \\
\hline Albumin $(g / L)$ & $36.9 \pm 5.0$ & $37.2 \pm 4.7$ \\
\hline Creatinine (umol/L) & $66.8 \pm 43.1$ & $68.3 \pm 27.1$ \\
\hline NT-proBNP (pg/mL) & $90.8 \pm 82.4$ & $107.4 \pm 87.9$ \\
\hline
\end{tabular}

Notes: Data are presented as mean \pm standard deviation or No. (\%).

Abbreviations: APACHE, Acute Physiology and Chronic Health Evaluation; BE, base excess; COPD, chronic obstructive pulmonary disease; CAT score, COPD assessment test score; COT, conventional oxygen therapy; FEVI, forced expiratory volume in one second; $\mathrm{FVC}$, forced vital capacity; $\mathrm{FiO}_{2}$, fraction of inspired oxygen; HFNC, high-flow nasal cannula; NT-proBNP, N-terminal pro-brain natriuretic peptide; $\mathrm{PaO}_{2}$, partial pressure of oxygen; $\mathrm{PaCO}_{2}$, partial pressure of carbon dioxide.

\section{Application and Side Effects of HFNC}

In terms of parameter settings in the HFNC group, the average gas flow rate was $33.4 \pm 5.6 \mathrm{~L} / \mathrm{min}, \mathrm{FiO}_{2}$ was 0.28 \pm 0.01 , and the temperature was $33.8 \pm 4.1^{\circ} \mathrm{C}$ (Table S3) In general, HFNC was well tolerated by the participants.
The most commonly reported side effects were condensate noise (26.3\%), excessive or insufficient gas flow (23.1\%), and high temperature (14.4\%). There were no significant differences in side effects between the HFNC success group and the failure group. All the side effects were resolved by adjusting the parameters or communicating with the participants (Table 6).

\section{Discussion}

To the best of our knowledge, this study was the first prospective, multicenter, randomized, controlled clinical trial to explore the efficacy and safety of HFNC in AECOPD patients with acute compensated hypercapnic respiratory failure. In this study, compared with oxygen therapy by nasal catheter, we found that HFNC could significantly prevent the worsening of respiratory failure in AECOPD patients, and HFNC patients were also more comfortable. However, there was no difference in the longterm outcomes. The side effects of HFNC were very obvious, but the patients did not choose to terminate their treatment because of side effects. Moreover, a $\mathrm{PaCO}_{2}>59 \mathrm{mmHg}$ after HFNC treatment for 24 $\mathrm{h}$ was an independent risk factor for treatment failure.

HFNC has many physiological advantages, which have popularized it in the treatment of adult respiratory failure in recent years. ${ }^{16}$ It effectively delivers humidified and heated gas to the airway. ${ }^{17}$ Moreover, the adequate flow and warm and humidified gas provided by HFNC can attenuate inspiratory resistance and increase expiratory resistance. ${ }^{18-20}$ High flows wash out $\mathrm{CO}_{2}$ and can reduce dead space, allowing for higher fraction-of-a-minute ventilation to facilitate gas exchange. ${ }^{21}$ Although HFNC is an open system, it can produce a certain level of positive airway pressure. ${ }^{22,23}$ These positive physiological mechanisms may also show promise in patients with AECOPD. ${ }^{24}$

Some studies have also explored the physiological effects of HFNC in patients of COPD. HFNC could decrease the neuroventilatory drive and work of breathing in patients with COPD compared with COT. ${ }^{25}$ Our previous study indicated that some patients with mild AECOPD may already have severe respiratory muscle fatigue, although they do not have severe respiratory failure. ${ }^{6}$ Therefore, based on our study results and previous studies on the physiological benefit of HFNC, we concluded that early use of HFNC in patients with AECOPD with acute compensated hypercapnic respiratory failure could alleviate respiratory muscle fatigue and improve $\mathrm{CO}_{2}$ retention, thereby reducing treatment failure. 
Table 2 Primary Endpoint and Secondary Endpoints in the Two Groups

\begin{tabular}{|c|c|c|c|c|}
\hline Outcome & All Patients $(n=320)$ & HFNC Group $(n=160)$ & COT Group $(n=160)$ & $\boldsymbol{P}$ \\
\hline \multicolumn{5}{|l|}{ Primary end point } \\
\hline Treatment failure, need of NIV, no. (\%) & $47(14.7)$ & $16(10.0)$ & $31(19.4)$ & 0.026 \\
\hline \multicolumn{5}{|l|}{ Secondary end point } \\
\hline Patients received NIV, no. (\%) & $39(12.2)$ & $13(8.1)$ & $26(16.3)$ & 0.039 \\
\hline CAT scores at discharge & $15.2 \pm 7.8$ & $12.0 \pm 7.6$ & $17.0 \pm 7.3$ & 0.002 \\
\hline Subjective discomfort score & $3.3 \pm 1.6$ & $2.3 \pm 1.1$ & $3.9 \pm 1.6$ & $<0.001$ \\
\hline Hospital lengths of stay (days) & $12.7 \pm 4.8$ & $12.2 \pm 5.3$ & $12.9 \pm 4.5$ & 0.453 \\
\hline Readmission rate within 3 months, no. (\%) & $77(24.1)$ & $32(20.0)$ & $45(28.1)$ & 0.116 \\
\hline \multicolumn{5}{|l|}{ Reason for NIV } \\
\hline Respiratory acidosis & $36(11.3)$ & $12(7.5)$ & $24(15.0)$ & 0.050 \\
\hline Obvious dyspnea & $\mathrm{II}(3.4)$ & $4(2.5)$ & $7(4.4)$ & 0.542 \\
\hline
\end{tabular}

Notes: Data are presented as mean \pm standard deviation or No. (\%). Treatment failure was defined as worsening of the patients' condition to the point that noninvasive or invasive mechanical ventilation was required.

Abbreviations: CAT score, COPD assessment test score; COT, conventional oxygen therapy; HFNC, high-flow nasal cannula oxygen therapy; NIV, noninvasive mechanical ventilation.

HFNC could reduce the $\mathrm{PaCO}_{2}$ and respiratory rate compared with COT in stable COPD cases. ${ }^{26,27}$ Fraser's team found that tidal volume and end-expiratory lung impedance were significantly higher in stable COPD cases with HFNC. ${ }^{28}$ Similarly, $\mathrm{PaCO}_{2}$ reduction was also observed in some smallsample-size cross-over studies of AECOPD cases. ${ }^{11}$ In this study, we found that the $\mathrm{PaCO}_{2}$ and respiratory rate in the
HFNC group were lower than those in the COT group after 24 $\mathrm{h}$ of therapy. Moreover, the treatment failure rate during hospitalization of the HFNC group was significantly lower than that in the COT group. We also found that the CAT score of the HFNC group was significantly lower than that in the COT group, indicating that HFNC may have the potential to improve the symptom of dyspnea in patients with AECOPD.

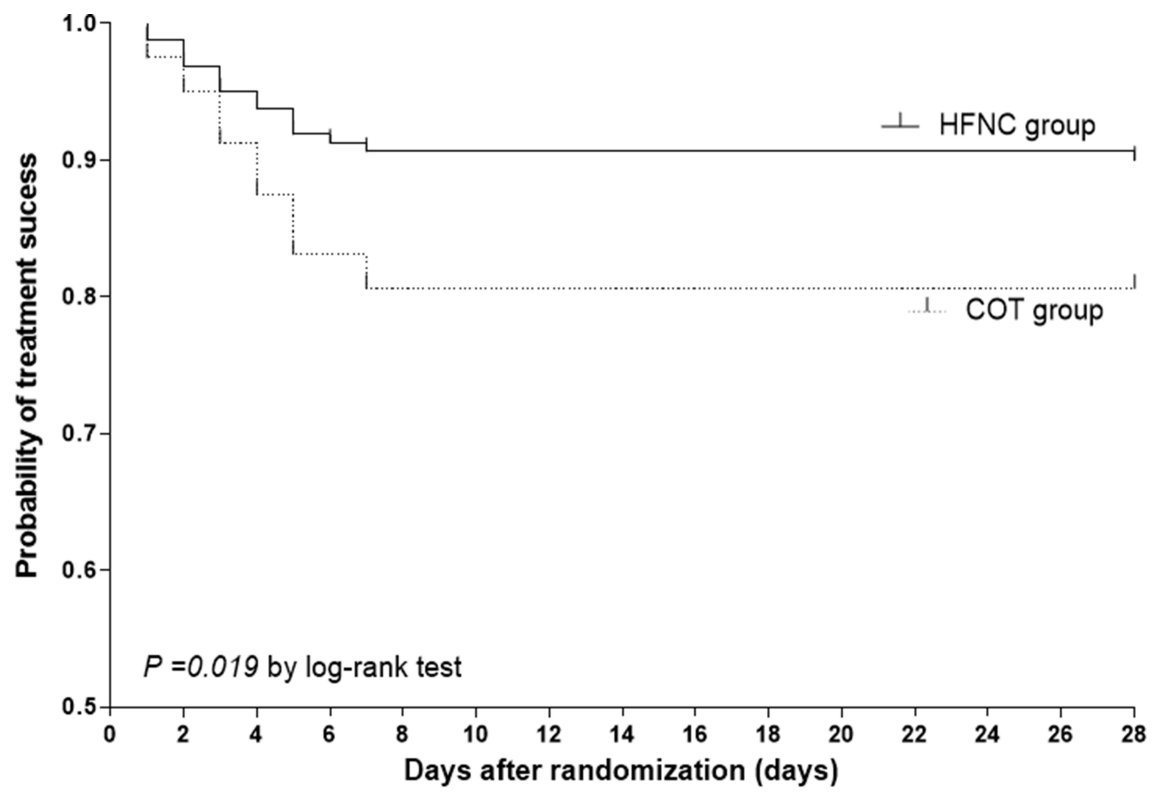

\begin{tabular}{|c|c|c|c|c|c|c|c|c|}
\hline \multicolumn{9}{|l|}{ NO. at risk } \\
\hline HFNC group & 160 & 150 & 144 & 144 & 144 & 144 & 144 & 144 \\
\hline СOT group & 160 & 140 & 129 & 129 & 129 & 129 & 129 & 129 \\
\hline
\end{tabular}

Figure 2 Kaplan-Meier estimates of the probability of treatment success at $28 \mathrm{~d}$ between the high-flow nasal cannula oxygen therapy (HFNC) group and the conventional oxygen therapy (COT) group. Significant differences were found for the cumulative probability of treatment success for the two groups (Log rank test: $p=0.019)$. 
Table 3 Comparison of Physiological Parameters Between HFNC and COT Groups

\begin{tabular}{|c|c|c|c|c|c|c|c|c|}
\hline Characteristic & Group & Baseline & $24 \mathrm{~h}$ & $48 \mathrm{~h}$ & $72 \mathrm{~h}$ & $120 \mathrm{~h}$ & Before Discharge & $p^{a}$ \\
\hline \multirow{3}{*}{$\mathrm{pH}$} & HFNC & $7.38 \pm 0.04$ & $7.36 \pm 0.06$ & $7.40 \pm 0.04$ & $7.41 \pm 0.05$ & $7.40 \pm 0.04$ & $7.40 \pm 0.04$ & 0.864 \\
\hline & СOT & $7.39 \pm 0.04$ & $7.38 \pm 0.05$ & $7.39 \pm 0.05$ & $7.39 \pm 0.05$ & $7.39 \pm 0.03$ & $7.39 \pm 0.04$ & 0.924 \\
\hline & $p^{c}$ & 0.376 & 0.730 & 0.182 & 0.049 & 0.017 & 0.530 & $0.888^{\mathrm{b}}$ \\
\hline \multirow[t]{3}{*}{$\mathrm{PaO}_{2}(\mathrm{mmHg})$} & HFNC & $54.7 \pm 5.2$ & $71.3 \pm 14.0$ & $70.5 \pm 13.8$ & $68.9 \pm 10.7$ & $69.4 \pm 10.6$ & $64.9 \pm 7.5$ & 0.000 \\
\hline & COT & $54.9 \pm 4.9$ & $73.8 \pm 9.2$ & $73.1 \pm 10.4$ & $70.9 \pm 5.6$ & $71.1 \pm 6.0$ & $64.3 \pm 5.4$ & 0.000 \\
\hline & $p^{c}$ & 0.680 & 0.119 & 0.143 & 0.151 & 0.237 & 0.578 & $0.219^{b}$ \\
\hline \multirow[t]{3}{*}{$\mathrm{PaCO}_{2}(\mathrm{mmHg})$} & HFNC & $54.9 \pm 7.1$ & $54.1 \pm 9.8$ & $52.8 \pm 7.9$ & $53.3 \pm 8.3$ & $52.1 \pm 10.2$ & $51.4 \pm 7.2$ & 0.001 \\
\hline & СOT & $54.2 \pm 6.0$ & $56.9 \pm 10.1$ & $54.1 \pm 8.6$ & $54.1 \pm 8.7$ & $54.4 \pm 10.2$ & $49.1 \pm 9.7$ & 0.034 \\
\hline & $p^{c}$ & 0.325 & 0.030 & 0.320 & 0.496 & 0.173 & 0.108 & $0.306^{\mathrm{b}}$ \\
\hline \multirow[t]{3}{*}{$\mathrm{SaO}_{2}(\%)$} & HFNC & $89.3 \pm 4.7$ & $92.8 \pm 3.0$ & $93.2 \pm 2.1$ & $93.0 \pm 3.4$ & $93.8 \pm 2.7$ & $92.2 \pm 3.4$ & 0.000 \\
\hline & СОT & $89.0 \pm 4.6$ & $93.5 \pm 2.7$ & $93.7 \pm 2.2$ & $93.6 \pm 2.7$ & $94.1 \pm 2.5$ & $92.8 \pm 3.5$ & 0.000 \\
\hline & $p^{c}$ & 0.649 & 0.079 & 0.111 & 0.185 & 0.395 & 0.227 & $0.325^{b}$ \\
\hline \multirow[t]{3}{*}{ Respiratory rate (bpm) } & HFNC & $21.0 \pm 1.7$ & $21.5 \pm 2.0$ & $21.4 \pm 2.4$ & $22.4 \pm 5.7$ & $21.4 \pm 2.5$ & $21.5 \pm 2.7$ & 0.066 \\
\hline & COT & $21.1 \pm 1.9$ & $23.1 \pm 7.6$ & $22.4 \pm 5.7$ & $21.8 \pm 2.2$ & $21.8 \pm 2.3$ & $21.4 \pm 1.9$ & 0.024 \\
\hline & $p^{c}$ & 0.790 & 0.024 & 0.067 & 0.294 & 0.253 & 0.628 & $0.150^{\mathrm{b}}$ \\
\hline
\end{tabular}

Notes: Results are mean \pm SD. Total number of patients present in each group at each time point. $p^{\mathrm{a}}$ for overall comparisons of differences in each group over time. $p^{b}$ for overall comparisons of differences between groups over time. $p^{c}$ for comparisons of differences between groups at each time point.

Abbreviations: COT, conventional oxygen therapy; $\mathrm{HFNC}$, high-flow nasal cannula oxygen therapy; $\mathrm{PaO}_{2}$, partial pressure of oxygen; $\mathrm{PaCO}{ }_{2}$, partial pressure of carbon dioxide; $\mathrm{SaO}_{2}$, arterial oxygen saturation.

AECOPD is primarily induced through infection. HFNC effectively provides humidified and heated gas to the airway, which can help improve mucus properties and
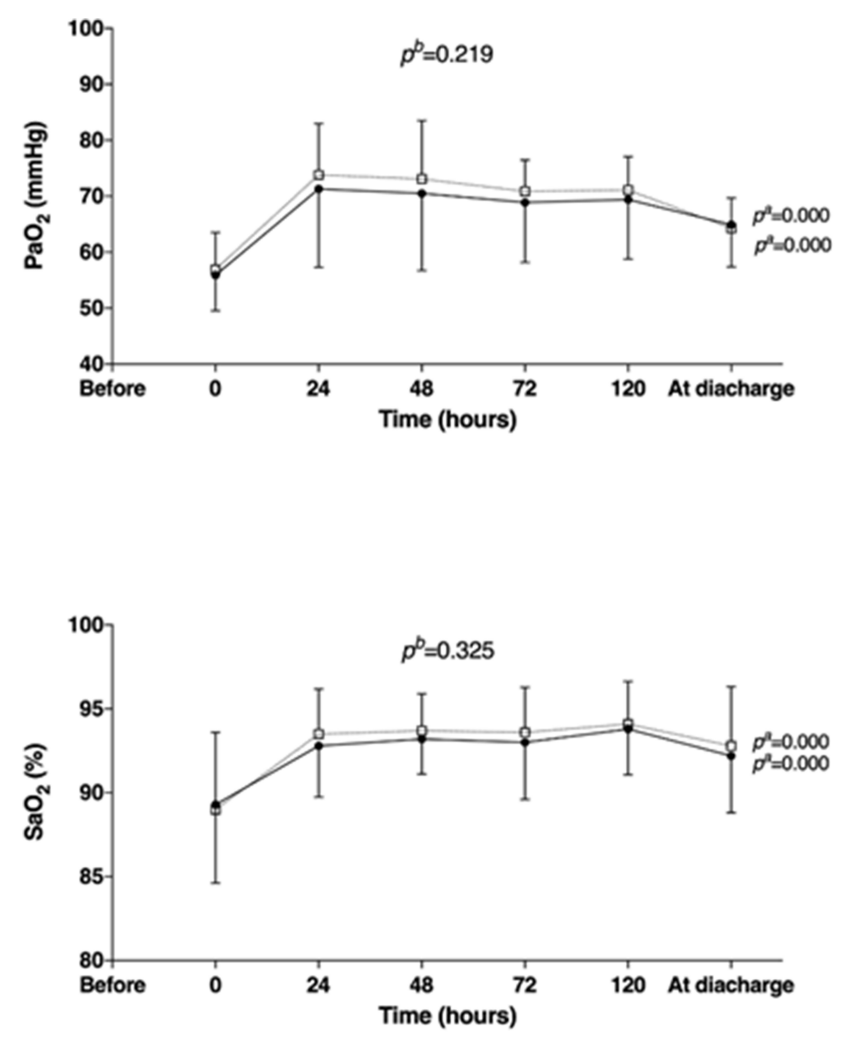

transport in AECOPD patients. ${ }^{29}$ Furthermore, HFNC has been shown in some research to be more comfortable than COT and NIV. ${ }^{11,30}$ This study showed that HFNC had
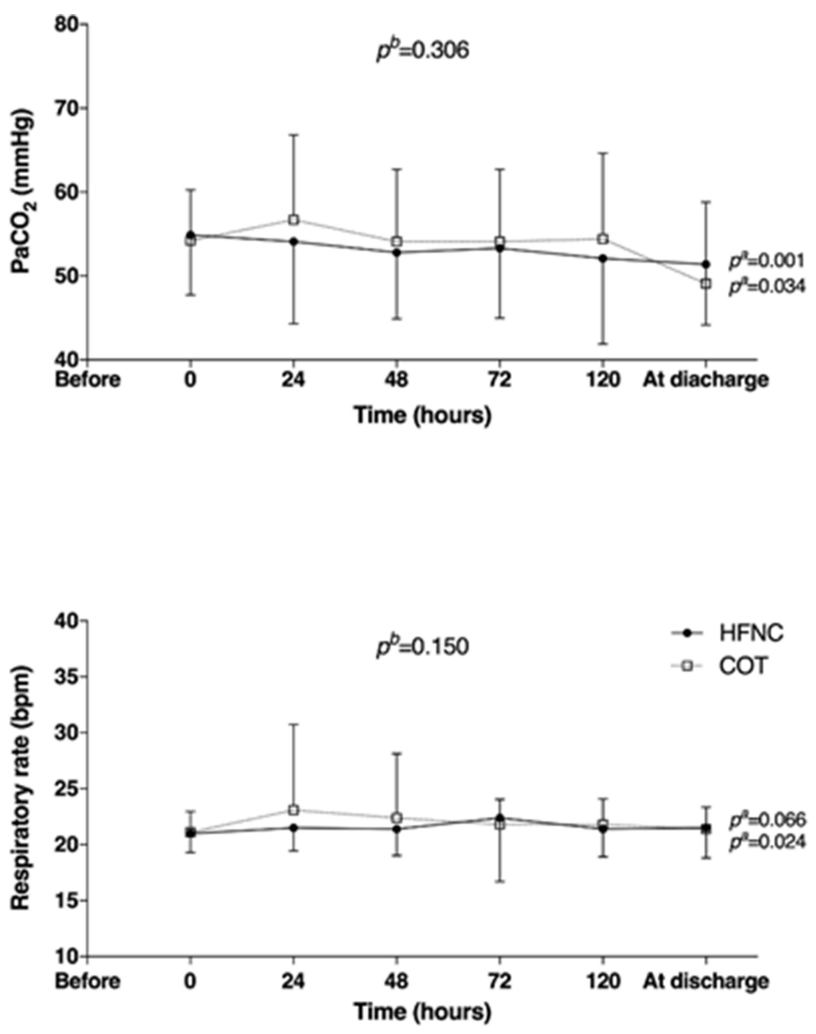

Figure 3 Comparison of physiological parameters between the high-flow nasal cannula oxygen therapy (HFNC) group and the conventional oxygen therapy (COT) group. Shown are the time courses of partial pressure of arterial oxygen $\left(\mathrm{PaO}_{2}\right)$, partial pressure of arterial carbon dioxide $\left(\mathrm{PaCO}_{2}\right)$, arterial oxygen saturation $\left(\mathrm{SaO} \mathrm{O}_{2}\right)$, and respiratory rate. $\mathrm{P}^{\mathrm{a}}$ represents the overall comparison of differences in each group over time, and $p^{b}$ represents overall comparisons of differences between groups over time. 
Table 4 Comparison of Physiological Parameters Between HFNC Success and Failure Groups

\begin{tabular}{|c|c|c|c|c|c|c|c|}
\hline Characteristic & HFNC Group & Baseline & $24 \mathrm{~h}$ & $48 \mathrm{~h}$ & $72 \mathrm{~h}$ & $120 \mathrm{~h}$ & $p^{a}$ \\
\hline \multirow[t]{3}{*}{$\mathrm{pH}$} & Success & $7.38 \pm 0.05$ & $7.40 \pm 0.04$ & $7.40 \pm 0.04$ & $7.4 I \pm 0.04$ & $7.41 \pm 0.04$ & 0.253 \\
\hline & Failure & $7.40 \pm 0.04$ & $7.38 \pm 0.04$ & $7.39 \pm 0.02$ & $7.38 \pm 0.06$ & $7.37 \pm 0.07$ & 0.197 \\
\hline & $p^{c}$ & $0.28 I$ & 0.334 & 0.756 & 0.018 & 0.030 & $0.050^{\mathrm{b}}$ \\
\hline \multirow[t]{3}{*}{$\mathrm{PaO}_{2}(\mathrm{mmHg})$} & Success & $54.8 \pm 4.8$ & $72.1 \pm 8.7$ & $70.6 \pm 14.0$ & $71.3 \pm 15.5$ & $71.2 \pm 16.4$ & 0.000 \\
\hline & Failure & $54.9 \pm 5.0$ & $71.2 \pm 11.7$ & $68.1 \pm 10.3$ & $68.9 \pm 15.2$ & $78.2 \pm 25.1$ & 0.487 \\
\hline & $p^{c}$ & 0.518 & 0.786 & 0.649 & 0.629 & 0.384 & $0.878^{\mathrm{b}}$ \\
\hline \multirow[t]{3}{*}{$\mathrm{PaCO}_{2}(\mathrm{mmHg})$} & Success & $54.6 \pm 6.9$ & $52.4 \pm 8.0$ & $51.5 \pm 5.6$ & $52.2 \pm 7.2$ & $50.9 \pm 8.9$ & 0.000 \\
\hline & Failure & $58.0 \pm 8.9$ & $59.0 \pm 11.8$ & $55.8 \pm 5.6$ & $63.8 \pm 11.0$ & $68.7 \pm 13.2$ & 0.144 \\
\hline & $p^{c}$ & 0.086 & 0.006 & 0.012 & 0.006 & 0.000 & $0.000^{\mathrm{b}}$ \\
\hline \multirow[t]{3}{*}{$\mathrm{SaO}_{2}(\%)$} & Success & $89.1 \pm 4.7$ & $93.3 \pm 2.7$ & $93.3 \pm 2.2$ & $93.1 \pm 3.3$ & $93.7 \pm 2.6$ & 0.000 \\
\hline & Failure & $90.5 \pm 4.8$ & $92.9 \pm 1.9$ & $92.3 \pm 2.5$ & $92.2 \pm 4.1$ & $95.4 \pm 4.2$ & 0.160 \\
\hline & $p^{c}$ & 0.295 & 0.592 & 0.237 & 0.460 & 0.179 & $0.628^{\mathrm{b}}$ \\
\hline Respiratory & Success & $20.1 \pm 1.5$ & $21.3 \pm 2.3$ & $22.4 \pm 5.9$ & $21.8 \pm 2.8$ & $21.4 \pm 2.4$ & 0.013 \\
\hline \multirow[t]{2}{*}{ rate (bpm) } & Failure & $22.4 \pm 2.5$ & $22.7 \pm 2.6$ & $22.0 \pm 2.8$ & $23.0 \pm 2.4$ & $21.5 \pm 1.9$ & 0.896 \\
\hline & $p^{c}$ & 0.032 & 0.059 & 0.829 & 0.205 & 0.936 & $0.784^{b}$ \\
\hline
\end{tabular}

Notes: Results are mean \pm SD. Total number of patients present in each group at each time point. $p^{a}$ for overall comparisons of differences in each group over time. $p^{b}$ for overall comparisons of differences between groups over time. $p^{c}$ for comparisons of differences between groups at each time point.

Abbreviations: HFNC, high-flow nasal cannula oxygen therapy; $\mathrm{PaO}_{2}$, partial pressure of oxygen; $\mathrm{PaCO}_{2}$, partial pressure of carbon dioxide; SaO

a higher comfort score than COT, which may lead to better patient compliance with treatment. Therefore, better airway management and treatment adherence by patients may also contribute to the lower treatment failure rate in those with AECOPD. However, in this study, we found that $\mathrm{PaCO}_{2}>59 \mathrm{mmHg}$ at $24 \mathrm{~h}$ after $\mathrm{HFNC}$ was an
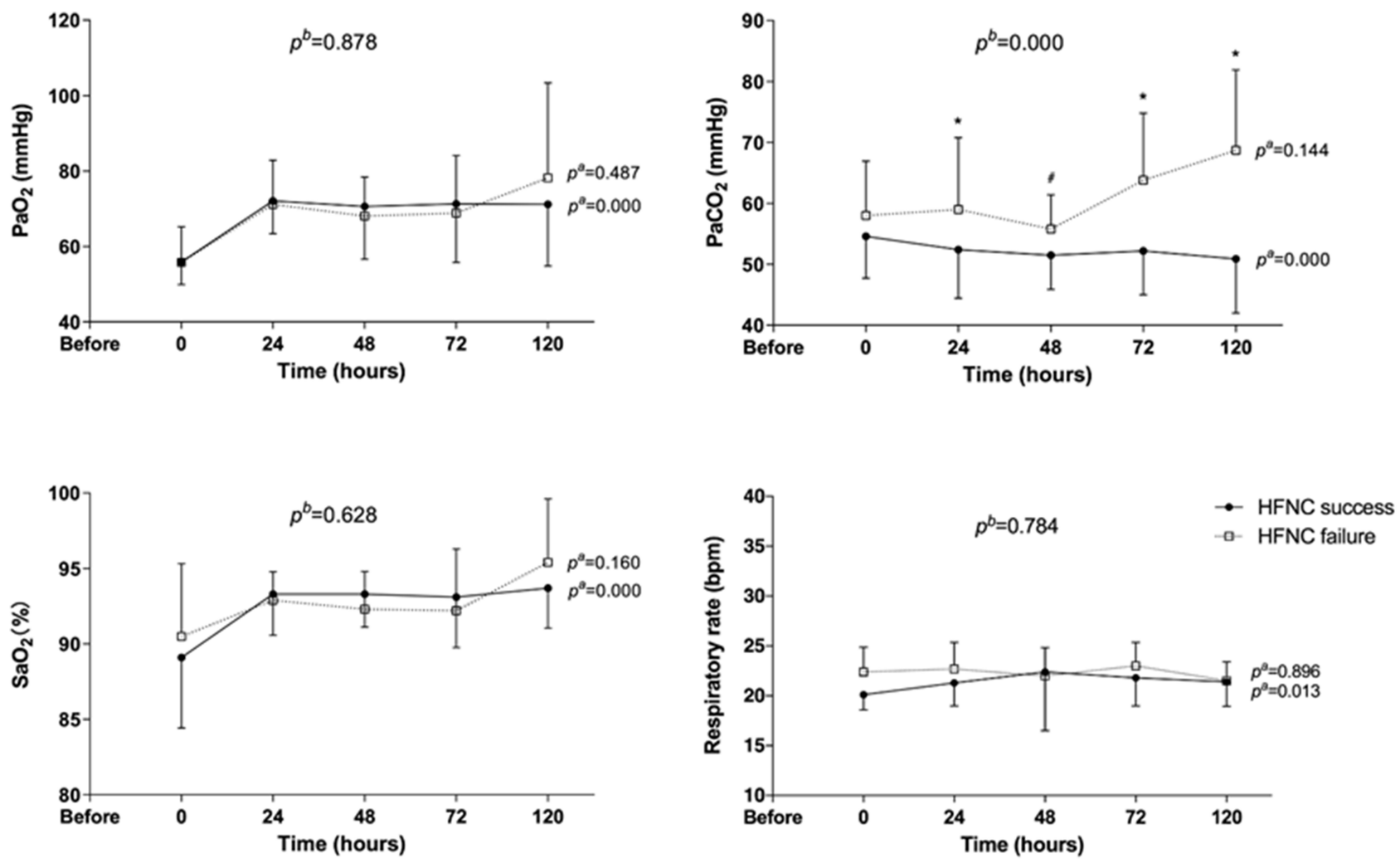

Figure 4 Comparison of physiological parameters between high-flow nasal cannula oxygen therapy success and failure groups. Shown are the time courses of partial pressure of arterial oxygen $\left(\mathrm{PaO}_{2}\right)$, partial pressure of arterial carbon dioxide $\left(\mathrm{PaCO}_{2}\right)$, arterial oxygen saturation $(\mathrm{SaO})$, and respiratory rate. $\mathrm{p}^{\mathrm{a}}$ represents overall comparisons of differences in each group over time, and $\mathrm{p}^{\mathrm{b}}$ represents overall comparisons of differences between groups over time. 
Table 5 Risk Factors Associated with HFNC Failure in Multivariate Analysis

\begin{tabular}{|l|l|l|l|l|}
\hline Variable & Wald & Odds Ratios & 95\% Confidence Interval & $P$ \\
\hline Univariate logistic regression & & & & \\
$\quad$ Respiratory rate $>22$ breaths per minute & 8.807 & 1.562 & $1.163-2.097$ & 0.003 \\
$\mathrm{PaCO}_{2}(24 \mathrm{~h})>59 \mathrm{mmHg}$ & 6.775 & 1.079 & $1.019-1.143$ & 0.009 \\
$\mathrm{PaCO}_{2}(48 \mathrm{~h})>55 \mathrm{mmHg}$ & 5.794 & 1.139 & $1.024-1.267$ & 0.016 \\
\hline Multivariate logistic regression & & & & \\
$\mathrm{PaCO}_{2}(24 \mathrm{~h})>59 \mathrm{mmHg}$ & 4.590 & 1.078 & $1.006-1.154$ & 0.032 \\
\hline
\end{tabular}

Abbreviations: HFNC, high-flow nasal cannula oxygen therapy; $\mathrm{PaO}_{2}$, partial pressure of oxygen; $\mathrm{PaCO}_{2}$, partial pressure of carbon dioxide.

Table 6 Side Effects of HFNC Treatment

\begin{tabular}{|c|c|c|c|c|c|}
\hline Side Effects & Treatment Measures & $\begin{array}{l}\text { HFNC Group } \\
(n=160)\end{array}$ & $\begin{array}{l}\text { HFNC Success Group } \\
(n=144, \%)\end{array}$ & $\begin{array}{l}\text { HFNC Failure Group } \\
(n=16, \%)\end{array}$ & $\boldsymbol{P}$ \\
\hline Condensate noise & Clear the water in the pipeline in time & 43 & $38(26.4)$ & $5(31.2)$ & 0.767 \\
\hline $\begin{array}{l}\text { Excessive or } \\
\text { insufficient gas flow }\end{array}$ & $\begin{array}{l}\text { Adjust appropriate flow according to } \\
\text { patient comfort }\end{array}$ & 38 & $32(22.2)$ & $6(37.5)$ & 0.214 \\
\hline Temperature too high & Adjust the appropriate temperature gear & 23 & $20(\mid 3.9)$ & $3(18.8)$ & 0.705 \\
\hline $\begin{array}{l}\text { Abnormal smell of } \\
\text { nasal cannula }\end{array}$ & Communicate and explain with patients & 4 & $3(2.1)$ & $\mathrm{I}(6.2)$ & 0.347 \\
\hline $\begin{array}{l}\text { Dizziness and } \\
\text { vomiting }\end{array}$ & $\begin{array}{l}\text { Refuse to continue application after } 72 \\
\text { hours of treatment }\end{array}$ & I & I & 0 & - \\
\hline $\begin{array}{l}\text { Dryness of } \\
\text { oropharynx }\end{array}$ & $\begin{array}{l}\text { The humidification effect is not achieved, } \\
\text { improved after reset }\end{array}$ & 1 & I & 0 & - \\
\hline
\end{tabular}

Abbreviation: HFNC, high-flow nasal cannula oxygen therapy.

independent risk factor of treatment failure, but with a relatively low sensitivity. Therefore, we suggest that in addition to optimized COPD therapy, appropriate oxygenation devices should be used on select patients to achieve the most optimal outcome.

This study had several limitations. First, although this was a multicenter, randomized, controlled trial, all the patients were enrolled from three hospitals in one city, and the enrollment numbers were unevenly distributed because of the different patient volumes at each hospital, which may have led to a regional bias. Second, the sample size was calculated based on a previous study. Due to the standardization of the management of COPD year by year, there might be differences compared with current data. Third, the cost of treatment was not considered in this study, so the real clinical benefit and cost-effectiveness ratio could not be determined; this will be included in future work. Finally, this study only focused on patients with compensated hypercapnic respiratory failure. No patients received IMV and no patients died, so it was difficult to assess the risk of mortality and IMV of the application of HFNC.

\section{Conclusions}

In AECOPD patients with acute compensated hypercapnic respiratory failure, HFNC could improve the prognosis compared with conventional oxygen therapy. Therefore, HFNC could be considered as an alternative to conventional oxygen therapy for first-line oxygen therapy in select patients. However, it should be cautiously applied to patients with moderate or severe hypercapnia, who were shown to have a high risk of treatment failure. Highquality randomized controlled trials in large-scale crossregional areas can further investigate the efficacy and safety of HFNC in a broader patient population with COPD exacerbation, which can also help identify the most appropriate patients and best practices.

\section{Data Sharing Statement}

Individual participant data that underlie the results reported in this article, after deidentification (text, tables, figures and appendices) will be shared. The study protocol, statistical analysis plan, informed consent form, clinical study report, and analytic codes will be available. Data can be acquired from the corresponding author for reasonable 
request beginning 3 months and ending 5 years following article publication.

\section{Ethics Approval and Consent to Participate}

The study was approved by the ethics committee of Beijing Chao-Yang Hospital and the other participating institutions, and informed consent was obtained from the patients themselves. This trial was conducted in accordance with the Declaration of Helsinki.

\section{Author Contributions}

All authors made a significant contribution to the work reported, whether that is in the conception, study design, execution, acquisition of data, analysis and interpretation, or in all these areas; took part in drafting, revising or critically reviewing the article; gave final approval of the version to be published; have agreed on the journal to which the article has been submitted; and agree to be accountable for all aspects of the work.

\section{Funding}

This work was supported by the Capital Health Research and Development of Specialties program of the Beijing Municipal Commission of Health and Family Planning (No. shoufa 2016-1-1061), the National Science and Technology Supporting Plan of the Ministry of Science and Technology of China (No. 2012BAI11B05), Xinjiang Science and Technology Projects (NO. 201591156), and the Program of Science and Technology of the Beijing Municipal (No. Z151100004015049).

\section{Disclosure}

The authors declare that they have no conflicts of interest.

\section{References}

1. Rabe KF, Hurd S, Anzueto A, et al. Global strategy for the diagnosis, management, and prevention of chronic obstructive pulmonary disease: GOLD executive summary. Am J Respir Crit Care Med. 2007;176(6):532-555. doi:10.1164/rccm.200703-456SO

2. Lozano R, Naghavi M, Foreman K, et al. Global and regional mortality from 235 causes of death for 20 age groups in 1990 and 2010: a systematic analysis for the global burden of disease study 2010. Lancet. 2012;380 (9859):2095-2128. doi:10.1016/S0140-6736(12)61728-0

3. Global Initiative for Chronic Obstructive Lung Disease. 2020 Global Strategy for Diagnosis, Management, and Prevention of COPD. 2020. http://www.goldcopd.org. Accessed November 18, 2020.

4. Brochard L, Mancebo J, Wysocki M, et al. Noninvasive ventilation for acute exacerbations of chronic obstructive pulmonary disease. $N$ Engl J Med. 1995;333(13):817-822. doi:10.1056/NEJM199509283331301
5. Plant PK, Owen JL, Elliott MW. Early use of non-invasive ventilation for acute exacerbations of chronic obstructive pulmonary disease on general respiratory wards: a multicentre randomised controlled trial. Lancet. 2000;355(9219):1931-1935. doi:10.1016/s0140-6736(00) 02323-0

6. Collaborative Research Group of Noninvasive Mechanical Ventilation for Chronic Obstructive Pulmonary D. Early use of non-invasive positive pressure ventilation for acute exacerbations of chronic obstructive pulmonary disease: a multicentre randomized controlled trial. Chin Med J. 2005;118(24):2034-2040.

7. Rochwerg B, Brochard L, Elliott MW, et al. Official ERS/ATS clinical practice guidelines: noninvasive ventilation for acute respiratory failure. Eur Respir J. 2017;50(2):2. doi:10.1183/13993003.02426-2016

8. Nava S, Navalesi P, Gregoretti C. Interfaces and humidification for noninvasive mechanical ventilation. Respir Care. 2009;54(1):71-84.

9. Papazian L, Corley A, Hess D, et al. Use of high-flow nasal cannula oxygenation in ICU adults: a narrative review. Intensive Care Med. 2016;42(9):1336-1349. doi:10.1007/s00134-016-4277-8

10. Pisani L, Fasano L, Corcione N, et al. Change in pulmonary mechanics and the effect on breathing pattern of high flow oxygen therapy in stable hypercapnic COPD. Thorax. 2017;72(4):373-375. doi:10.1136/thoraxjnl-2016-209673

11. Pilcher J, Eastlake L, Richards M, et al. Physiological effects of titrated oxygen via nasal high-flow cannulae in COPD exacerbations: a randomized controlled cross-over trial. Respirology. 2017;22 (6):1149-1155. doi:10.1111/resp.13050

12. Bruni A, Garofalo E, Cammarota G, et al. High flow through nasal cannula in stable and exacerbated chronic obstructive pulmonary disease patients. Rev Recent Clin Trials. 2019;14(4):247-260. doi:10.2174/1574887114666190710180540

13. Vogelmeier CF, Criner GJ, Martinez FJ, et al. Global strategy for the diagnosis, management, and prevention of chronic obstructive lung disease 2017 report. GOLD executive summary. Am J Respir Crit Care Med. 2017;195(5):557-582. doi:10.1164/rccm.201701-0218PP

14. Cai BQ, Cai SX, Chen RC, et al. Expert consensus on acute exacerbation of chronic obstructive pulmonary disease in the People's Republic of China. Int $J$ Chron Obstruct Pulmon Dis. 2014;9:381-395. doi:10.2147/COPD.S58454

15. Lee MK, Choi J, Park B, et al. High flow nasal cannulae oxygen therapy in acute-moderate hypercapnic respiratory failure. Clin Respir J. 2018;12(6):2046-2056. doi:10.1111/crj.12772

16. Lee JH, Rehder KJ, Williford L, Cheifetz IM, Turner DA. Use of high flow nasal cannula in critically ill infants, children, and adults: a critical review of the literature. Intensive Care Med. 2013;39 (2):247-257. doi:10.1007/s00134-012-2743-5

17. Chidekel A, Zhu Y, Wang J, Mosko JJ, Rodriguez E, Shaffer TH. The effects of gas humidification with high-flow nasal cannula on cultured human airway epithelial cells. Pulm Med. 2012;2012:380686. doi:10.1155/2012/380686

18. Cirio S, Piran M, Vitacca M, et al. Effects of heated and humidified high flow gases during high-intensity constant-load exercise on severe COPD patients with ventilatory limitation. Respir Med. 2016;118:128-132. doi:10.1016/j.rmed.2016.08.004

19. Dysart K, Miller TL, Wolfson MR, Shaffer TH. Research in high flow therapy: mechanisms of action. Respir Med. 2009;103 (10):1400-1405. doi:10.1016/j.rmed.2009.04.007

20. Mundel T, Feng S, Tatkov S, Schneider H. Mechanisms of nasal high flow on ventilation during wakefulness and sleep. $J$ Appl Physiol (1985). 2013;114(8):1058-1065. doi:10.1152/japplphysiol.01308. 2012

21. Moller W, Celik G, Feng S, et al. Nasal high flow clears anatomical dead space in upper airway models. J Appl Physiol (1985). 2015;118 (12):1525-1532. doi:10.1152/japplphysiol.00934.2014

22. Parke R, McGuinness S, Eccleston M. Nasal high-flow therapy delivers low level positive airway pressure. Br J Anaesth. 2009;103 (6):886-890. doi:10.1093/bja/aep280 
23. Groves N, Tobin A. High flow nasal oxygen generates positive airway pressure in adult volunteers. Aust Crit Care. 2007;20 (4):126-131. doi:10.1016/j.aucc.2007.08.001

24. Pisani L, Vega ML. Use of nasal high flow in stable COPD: rationale and physiology. COPD. 2017;14(3):346-350. doi:10.1080/ 15412555.2017 .1315715

25. Di Mussi R, Spadaro S, Stripoli T, et al. High-flow nasal cannula oxygen therapy decreases postextubation neuroventilatory drive and work of breathing in patients with chronic obstructive pulmonary disease. Crit Care. 2018;22(1):180. doi:10.1186/s13054-018-2107-9

26. Nagata K, Kikuchi T, Horie T, et al. Domiciliary high-flow nasal cannula oxygen therapy for patients with stable hypercapnic chronic obstructive pulmonary disease. a multicenter randomized crossover trial. Ann Am Thorac Soc. 2018;15(4):432-439. doi:10.1513/ AnnalsATS.201706-425OC

27. Vogelsinger H, Halank M, Braun S, et al. Efficacy and safety of nasal high-flow oxygen in COPD patients. BMC Pulm Med. 2017;17 (1):143. doi:10.1186/s12890-017-0486-3
28. Fraser JF, Spooner AJ, Dunster KR, Anstey CM, Corley A. Nasal high flow oxygen therapy in patients with COPD reduces respiratory rate and tissue carbon dioxide while increasing tidal and end-expiratory lung volumes: a randomised crossover trial. Thorax. 2016;71(8):759-761. doi:10.1136/thoraxjnl-2015-207962

29. Hasani A, Chapman TH, McCool D, Smith RE, Dilworth JP, Agnew JE. Domiciliary humidification improves lung mucociliary clearance in patients with bronchiectasis. Chron Respir Dis. 2008;5 (2):81-86. doi:10.1177/1479972307087190

30. McKinstry S, Singer J, Baarsma JP, Weatherall M, Beasley R, Fingleton J. Nasal high-flow therapy compared with non-invasive ventilation in COPD patients with chronic respiratory failure: a randomized controlled cross-over trial. Respirology. 2019;24 (11):1081-1087. doi:10.1111/resp.13575

\section{Publish your work in this journal}

The International Journal of COPD is an international, peer-reviewed journal of therapeutics and pharmacology focusing on concise rapid reporting of clinical studies and reviews in COPD. Special focus is given to the pathophysiological processes underlying the disease, intervention programs, patient focused education, and self management protocols. This journal is indexed on PubMed Central, MedLine and CAS. The manuscript management system is completely online and includes a very quick and fair peer-review system, which is all easy to use. Visit http://www.dovepress.com/testimonials.php to read real quotes from published authors. 